\title{
The antisense protein of HTLV-2 positively modulates HIV-1 replication
}

\author{
Cynthia Torresilla ${ }^{1 *}$, Sonia Do Carmo ${ }^{1}$, Émilie Larocque ${ }^{1}$, Estelle Douceron ${ }^{2}$, Jean-Michel Mesnard ${ }^{3}$, \\ Renaud Mahieux², Benoit Barbeau' \\ From 16th International Conference on Human Retroviruses: HTLV and Related Viruses \\ Montreal, Canada. 26-30 June 2013
}

Unlike HTLV-1, HTLV-2 does not induce leukemia and has been tentatively associated with an HTLV-1-associated myelopathy-like disorder. It has been reported that HTLV-2/HIV-1 co-infected patients progress less rapidly to AIDS than HIV-1-infected individuals. Tax2 has been suggested to mediate this protective state by inducing MIP- $1 \alpha$ expression and blocking HIV-1 infection. As cells from HTLV-2-infected individuals mainly express Antisense Protein 2 (APH-2), our objective was to determine if this protein might also intervene in controlling HIV-1 replication in dually infected individuals. Using Jurkat cells, we first demonstrated that both APH-2 and HBZ, the HTLV-1 analogue, equally induced MIP- $1 \alpha$ in unstimulated and stimulated Jurkat T cells. To assess if APH-2 might directly affect HIV-1 replication, a full length luciferase-expressing proviral DNA was tested in Jurkat cells. Surprisingly, upon co-transfection with an APH-2 expression vector, an increase in luciferase activity was observed, while HBZ expression rather led to reduced reporter gene expression. Western blot analyses and ELISA assay further indicated that HIV-1 p24 levels were more important in $\mathrm{APH}-2$-expressing cells. To determine if APH-2 was directly modulating HIV-1 LTR activity, both NF- $\kappa$ B and NFAT were tested in stimulated Jurkat cells. Unexpectedly, HBZ and APH-2 inhibited NF- $\kappa$ B and NFAT activation, albeit at different extent. In addition, LTR activation was also inhibited by both antisense proteins although APH-2 had a more modest effect. Our results thus highlight the complex interplay between HTLV antisense transcript-encoded proteins and HIV-1 expression and further studies will be required to determine the potential impact of APH-2 in HTLV-2/HIV-1-infected individuals.

\footnotetext{
* Correspondence: cynthia.torresilla@gmail.com

${ }^{1}$ Département des sciences biologiques and Centre de recherche BioMed,

Université du Québec à Montréal, Montréal (Québec) Canada

Full list of author information is available at the end of the article
}

\section{Authors' details}

'Département des sciences biologiques and Centre de recherche BioMed, Université du Québec à Montréal, Montréal (Québec) Canada. ${ }^{2}$ Oncogenèse Rétrovirale, Ligue Nationale Contre Le Cancer, CIRI, INSERM U1111-CNRS UMR5308, Université Lyon 1, Ecole Normale Supérieure de Lyon, LabEx ECOFECT, Lyon, Cedex 07, France. ${ }^{3}$ Université Montpellier 1, Centre d'études d'agents Pathogènes et Biotechnologies pour la Santé, CNRS, UM5236, Montpellier, France.

Published: 7 January 2014

doi:10.1186/1742-4690-11-S1-P118

Cite this article as: Torresilla et al:: The antisense protein of HTLV-2 positively modulates HIV-1 replication. Retrovirology 2014 11(Suppl 1): P118.
Submit your next manuscript to BioMed Central and take full advantage of:

- Convenient online submission

- Thorough peer review

- No space constraints or color figure charges

- Immediate publication on acceptance

- Inclusion in PubMed, CAS, Scopus and Google Scholar

- Research which is freely available for redistribution

Submit your manuscript at www.biomedcentral.com/submit
() Biomed Central 